and often changed, has been the usual application to the sores, whether chancres, abrasions, or ulcerated buboes. Creosote, in some more obstinate cases, has seemed to have exerted peculiar benefit. Buboes, in their incipient stage, bave been frequently discussed by cold stimulating lotions. But the most efficacious remedy has been the ceratum cantharidum applied over the tumor, and followed by repeated dressings of ceratum sabinæ. Another means has been that of renewing the ceratum canth. itself after the lapse of two or three days, and repeating it as soon as cicatrization had commenced. This method, even where suppuration has been established and an opening formed, has seemed to shorten the whole process of inflammation. Usually, however, a common bread and water poultice has been the principal application, where profuse suppuration has taken place in bubo. On the entrance of a patient with primary syphilis, with plethoric habit, venesection and free purgation, with the lowest diet, have been directed. Frequent saline laxatives and a low diet have been resorted to in all cases during the violence of the symptoms.

Cases of secondary syplilis have been treated according as one or another form of it presented. Secondary eruptions of the skin have in general yielded to the sulphur bath, assisted by lotions of chloride of soda or by the ointment of the ioduret of sulphur. Ulcerations have healed under lint wetted with chloride of soda, and covered with a poultice. Nodes have in every case vanished under the use of blisters: the irritation occasioned by which having been kept up by dressings of savin cerate, continued until the swelling has entirely subsided. The nocturnal pains, and all the other pains accompanying secondary syphilis, have been relieved (oftentimes immediately and completely) by the exhibition of the hydriodate of potass as lately recommended by Robert Williams, M.D. in vol. xiv. p. 39 of the London Medical Gazette.

\title{
SINGULAR CASE OF LOOSE CARTILAGES IN THE KNEE JOINT.
}

EY DANIFL M'RUER, M.D. BANGOR, MF.

[Communicated for the Boston Medical and Surgical Journal.]

Mrs. Whittier, of Corinth, in this State, aged about 30 years, and of a phlegmatic habit, was induced to consult me by the advice of her attending physician, Dr. Fuller, on account of a lameness occasioned by a diseased enlargement of the left knee joint, of upwards of fifteen years standing; and which has prevented her, for the last three or four years, from attending to her domestic duties, without great pain and inconvenience. Upon exanination, I found it to be one of the most extraordinary (judging from the number) cases of loose cartilages, that I have seen in practice, or met with in authors, and as her situation in life made it necessary for her to obtain relief, even at a risk, I recommended an operation, to which she assented; and a few days afterwards, with the assistance of Dr. F. I extracted from her knee thirty-four cartilaginous 
bodies, the largest measuring, in its longest diameter, one inch and a quarter; in its shortest, three fourths of an inch; and in thickness, one half inch. The others very gradually decreased in size, until the smallest approached to that of a large garden pea. The incision was made one inch and a half in length, on the inner side of the joint; there was about three ounces of synovia escaped, of an unusual thick consistence. The patient was placed in bed, and the leg supported with pillows, in a slightly flexed position, previous to the operation (that being the usual and most easy position of the limb), and was not moved for lour or five days after.

Since the operation, she has been under the care of Dr. F., from whom I learned, ten days after, that she was doing well; having had as little local inflammation, or general irritation, as ought to be expected from an irksome confinement.

From the very definite account which Mrs. W. gives of the growth of the cartilaginous bodies during their loose state, and from the fact that one of them exhibits another (smaller) united to it by a tendinous attachınent, I am disposed to question the correctness of their pathology as given by Hunter, Cruicksliank and Brodie, namely, that their growth only continues while they renain in inmediate contact with the synovial membrane, but suppose that they may possess a kind of organic vitali$t y$ after their separation, having acquired during their early formation an absorbing surface; and even that one may become the excrescence-like production of another.

A remarkable feature in this case, is the fact that so little inflammation or irritability followed the operation; which can only be explained by supposing that the parts had been so long habituated to the irritation of the morbid bodies, that their animal and organic sensibilities were blunted.

Bangor, Me. Nóv. 6, 1836.

\section{ON THE NATURE AND TREATMENT OF CALCULOUS DISEASES.}

BY BENJAMIN W. DUDLEY, M.D. LEXINGTON, KY.

[Concluded from page 239.]

Is performing the operation of lithotomy, it is always desirable with me to reach the groove in the staff, while this instrument is firmly held in a perpendicular attitude by the assistant; care being taken not to incline it either way from the centre of the perinæum. The instruction of some surgeons who require that the convexity of the staff be made prominent in the left side of the perinæum, in order that the incision shall be directed directly upon it, appears to me to be the result of false reasoning upon the subject.

An opening more central in the perinæum secures, to a greater extent, the facility of using forceps in the extraction of the stone; and after the patient is placed in bed, there is an advantage in the strait-lined character of the wound, from the superfices to the bladder. The neck of the 